\title{
Последствия пандемии COVID-19 для китайской инициативы «Один пояс, один путь»
}

\section{Фрэнк Моуриц}

Европейский центр исследований по вопросам безопасности им. Джорджа К. Маршалла, https://www.marshallcenter.org/en

Университет Бундесвера, Мюнхен, https://www.unibw.de/home-en

Резюме: В статье рассматриваются краткосрочные и долгосрочные последствия пандемии COVID-19 для инициативы «Один пояс, один путь» (ИМД - инициатива мостов и дорог). Временной срыв экономики по всему миру нарушил глобальные цепочки поставок, что вызвало серьезные задержки в реализации инфраструктурных проектов ИМД и увеличило затраты. В настоящее время Китаю и странам-партнерам ИМД придется отвлечь внимание и ресурсы на борьбу с распространением вируса и оказание помощи своим экономикам. Таким образом, серьезное замедление развития ИМД неизбежно. Однако долгосрочные последствия на данный момент все еще не ясны и в значительной степени будут зависеть от того, как долго коронавирус будет отбрасывать назад мировую экономику. Китай, похоже, полон решимости продолжать работу по ИМД, несмотря ни на что, но возникает вопрос, достаточно ли быстро восстановится экономика Китая и есть ли у Пекина финансовые резервы, чтобы поддерживать высокий уровень решимости осуществлять и обеспечивать ИМД. Если Китаю удастся поддерживать ИМД на протяжении всей пандемии, коронавирус может открыть возможности для использования «масочной дипломатии» и проектов инфраструктуры здравоохранения ИМД для укрепления глобального положения Пекина и локального признания ИМД. Учитывая изменившиеся обстоятельства, странам ИМД рекомендуется пересмотреть свое участие в ИМД, уделив должное внимание краткосрочным и возможным долгосрочным эффектам. Им следует подумать могут ли они по-прежнему позволить себе эти инфраструктурные проекты, даже если они требуют больше времени для завершения, являются более дорогостоящими и имеют меньший экономический эффект. 
Ключевые слова: Шелковый путь, COVID-19, экономические последствия, восстановление экономики, иностранные инвестиции.

\section{Введение}

Среди ученых широко распространено мнение, что одна из самых разрушительных пандемий в истории человечества, чума или черная смерть, возникла в Китае и распространилась по старому шелковому пути в Европу. ${ }^{1}$ Она продемонстрировала пример, который стар, как история человечества: когда люди и товары перемещаются, бактерии и вирусы тоже. Сегодня есть некоторые предположения о том, что COVID-19 распространялся по «новому шелковому пути» - Китайской инициативе «Один пояс, один путь» (ИМД), ${ }^{2}$ и даже высказывались предположения, что ИМД способствовала распространению вируса. ${ }^{3}$ Подобные споры бессмысленны, потому что даже без современных транспортных средств, таких как самолеты, грузовые корабли и поезда, чума достигла самых отдаленных уголков мира и унесла жизни значительной части населения планеты. Взаимосвязанность может ускорить распространение пандемии, но изоляция от торговых путей и международного обмена не является эффективной защитой, как демонстрирует распространение COVID-19 во всех частях мира.

Однако реальный недостаток взаимосвязанности и ее старшего брата, глобализации, заключается в том, что крупный глобальный сбой, такой как пандемия, имеет последствия, распространяющиеся волнами по всему миру. Неизбежно то, что глобальная инициатива по развитию инфраструктуры, такая как «Один пояс, один путь», сильно страдает от прерывания цепочек поставок и ограничений на международные поездки, вызванных коронавирусом. Под эгидой «Один пояс, один путь» Китай участвует в строительстве портов, железных дорог, автомагистралей, трубопроводов, электростанций, заводов и многих других видов экономической инфраструктуры. ИМД также включает в себя другие средства для увеличения глобальной взаимосвязанности Китая, такие как сотрудничество в области цифро-

1 Giovanna Morelli et al., "Yersinia pestis Genome Sequencing Identifies Patterns of Global Phylogenetic Diversity," Nature Genetics 42, no. 12 (October 2010): 1140-43, https://doi.org/10.1038/ng.705; Stephanie Haensch et al., "Distinct Clones of Yersinia pestis Caused the Black Death," PLoS Pathogens 6, no. 10 (October 2010), https://doi.org/10.1371/journal.ppat.1001134.

2 Salvatore Babones, "The 'Chinese Virus' Spread Along the New Silk Road," Foreign Policy, April 6, 2020 https://foreignpolicy.com/2020/04/06/chinese-coronavirusspread-worldwide-on-new-silk-road; Parag Khanna, "Covid-19 Is Traveling Along the New Silk Road," Wired, February 28, 2020, https://www.wired.com/story/covid-19-istraveling-along-the-new-silk-road.

3 Andreea Brînză, "Some Say China's Belt and Road Helped Create This Pandemic. Can It Prevent the Next One?" The Diplomat, April 2, 2020, https://thediplomat.com/ 2020/04/some-say-chinas-belt-and-road-helped-create-this-pandemic-can-itprevent-the-next-one. 
вых технологий, образования и общественного здравоохранения, но в основе инициативы лежит инфраструктура. Быстрый прогресс в развитии инфраструктуры жизненно важен для целей Китая по интеграции своей экономики в цепочки создания добавочной стоимости в Азии, на Ближнем Востоке, в Африке и Европе. Чем больше времени потребуется для налаживания связей между Китаем и странами ИМД, тем больше времени потребуется, прежде чем Китай сможет воспользоваться преимуществами своих обширных инвестиций в ИМД. Однако из-за пандемии инфраструктурные проекты ИМД сталкиваются с рядом серьезных проблем. Прерваны поставки сырья и приостановлено производство строительных компонентов. Некоторые рабочие не вышли на работу из-за мер изоляции или из-за боязни заразиться; в отдельных анекдотических сообщениях рассказывается о местных сотрудниках, которые отказались работать вместе с китайскими коллегами. Инженеры и проектировщики строительства не смогли выехать или находятся на карантине. Пандемия также демонстрирует особую уязвимость проектов ИМД: зависимость от Китая. Большинство проектов финансируется китайскими деньгами и выполняется китайскими строительными компаниями, в которых часто используется большая китайская рабочая сила. Таким образом, если экономика Китая испытывает трудности, то же самое происходит и с прогрессом ИМД. Более диверсифицированный подход, в большей степени опирающийся на местную экономику, упростил бы замену сырья, строительных деталей и рабочих. Пандемия по-прежнему будет иметь негативные последствия, но будет легче адаптироваться к новой ситуации.

\section{Китайские обещания противоречат суровой реальности}

Несмотря на очевидные проблемы, описанные выше, которые серьезно ставят под сомнение устойчивость ИМД в целом, китайская сторона сделала много официальных заявлений о приверженности к инициативе. Китай поспешил сообщить, что ИМД останется приоритетом политики даже во время пандемии COVID-19, а также после нее. Были даны заверения, что проекты ИМД не будут отменены или остановлены, и что не будет никаких задержек. Однако, учитывая глобальные последствия пандемии, партийным чиновникам пришлось признать, что для ИМД будут негативные последствия. В феврале 2020 года в официальной версии все еще говорилось, что ИМД «не пострадала» ${ }^{4}$ от коронавируса. Эта позиция сначала изменилась на «отсутствие серьезного воздействия на ИМД», ${ }^{5}$ а затем, в марте, на "временное

4 Zhong Nan, "BRI Projects Not Affected by Coronavirus, Official Says," China Daily, February 21, 2020, https://www.chinadaily.com.cn/a/202002/21/WS5e4f7970a310 $12821727952 \mathrm{f} . \mathrm{html}$.

5 Gao Yang, "No Serious Impact of Virus on BRI Projects," China Daily, March 4, 2020, https://www.chinadaily.com.cn/a/202003/04/WS5e5ee134a31012821727c0d3.html. 
воздействие на ИМД». ${ }^{6}$ В апреле, после того как большинство ограничений в Китае было снято, партия поспешила объявить, что китайские компании «перезапускают большинство зарубежных проектов». ${ }^{7}$ Эта формулировка интересна, потому что слово «перезапуск» указывает на то, что что-то было полностью остановлено и, хотя говорилось о «временном воздействии», никогда официально не признавалось, что работа над проектами ИМД остановилась.

Объявление о перезапуске ИМД явно противоречит сообщениям со всего мира, которые показывают, что большое количество проектов все еще приостановлено или может быть продолжено, но только гораздо более медленными темпами. Несмотря на официальные заверения в том, что Китайско-пакистанский экономический коридор (флагманский проект ИМД) «продвигается вперед полным ходом», ${ }^{8}$ правительству Пакистана в конечном итоге пришлось признать, что в его работе ожидаются серьезные сбои и задержки. ${ }^{9}$ Строительство высокоскоростной железной дороги, финансируемое Китайским банком развития (CDB) в Индонезии, ${ }^{10}$ и еще один железнодорожный проект в Нигерии ${ }^{11}$ приостановлены. Работа по особой экономической зоне в Камбодже почти полностью остановилась, ${ }^{12}$ а электростанция, которую строит китайская строительная компания, не смогла начать работу в мае 2020 года, как планировалось. ${ }^{13}$ Сообщается также о

6 Zhou Jin, "Virus Having Temporary Impact on BRI Construction, Minister Says," China Daily, March 5, 2020, https://www.chinadaily.com.cn/a/202003/05/WS5e60a0d7a31 012821727c9c5.html.

7 Yan Yunming, "Chinese Companies Restarting Most Overseas Projects amid COVID-19 Shows BRI Vitality," Global Times, March 23, 2020, http://www.globaltimes.cn/ content/1186577.shtml.

8 Wang Bozun, "CPEC to March Forward at Full Speed despite Pandemic: Pakistani FM," Global Times, March 19, 2020, http://www.globaltimes.cn/content/1183171.shtml.

9 Mehtab Haider, "CPEC Projects May Face Delay, Disruption: Report," The News International, April 25, 2020, https://www.thenews.com.pk/print/649536-cpec-projectsmay-face-delay-disruption-report.

10 George Liao, "'One Belt One Road' Begins to Stall in SE Asia as Chinese Economy Reels," Taiwan News, May 6, 2020, https://www.taiwannews.com.tw/en/news/ 3929303.

11 Daniel Russel, Asia Society Policy Institute, "The Coronavirus Will Not Be Fatal for China's Belt and Road Initiative but It Will Strike a Heavy Blow," South China Morning Post, March 19, 2020, https://www.scmp.com/comment/opinion/article/3075624/ coronavirus-will-not-be-fatal-chinas-belt-and-road-initiative-it.

12 Andre Wheeler, "COVID-19: Can China Offset the Long-Term Socio-Economic Impact on China's Belt Road Initiative?" Mizzima, April 15, 2020, http://mizzima.com/article/ covid-19-can-china-offset-long-term-socio-economic-impact-chinas-belt-roadinitiative.

13 Yohei Muramatsu and Shunsuke Tabeta, "Southeast Asia Rail Projects Stall as China Focuses on Recovery," Nikkei Asian Review, May 5, 2020, https://asia.nikkei.com/Spot light/Belt-and-Road/Southeast-Asia-rail-projects-stall-as-China-focuses-on-recovery. 
задержках на электростанциях в Мьянме и Бангладеше. ${ }^{14}$ Учитывая экономическую неопределенность, некоторые страны даже начали пересматривать проекты ИМД, которые уже были запущены или находятся на стадии планирования. Крупномасштабный проект по строительству моста в Бангладеше ставится под сомнение местными властями. ${ }^{15}$ Проект так называемого «шелкового города и пяти островов» в Кувейте, проект городского развития мегаполиса, также находится под угрозой, ${ }^{16}$ и Таиланд объявил, что хочет отложить проект высокоскоростного поезда, связывающего его с Китаем. ${ }^{17}$ Можно ожидать еще объявлений о задержках, остановках операций и повторных переговорах, поскольку операции возвращаются в нормальное состояние не быстро.

Даже когда будет достигнута нормализация работы цепочек поставок и международных поездок, маловероятно, что ИМД сможет продолжить работу в соответствии с планом. Китай, а также страны, присоединившиеся к ИМД, сталкиваются с серьезными экономическими проблемами из-за пандемии, которая может отвлечь внимание и ресурсы от ИМД.

\section{Перспективы Китая}

В настоящее время Китай настолько занят спасением своей внутренней экономики, что иностранным инвестициям, возможно, придется отойти на второй план. По данным Национального статистического бюро Китая, ВВП сократился на 6,8 \% в первом квартале 2020 года. ${ }^{18}$ Из-за очень сильных ограничительных мер блокировки по всему Китаю, большинство компаний были закрыты, а некоторые из них так и не открылись заново, и в январе и феврале 2020 года было объявлено о 240000 банкротств. Вероятно, еще многие компании обанкротились в течение этого периода, но не смогли объявить о банкротстве, потому что большинство государственных учреждений было закрыто в первые месяцы года. Числа, вероятно, вырастут еще больше, потому что 36 \% частных компаний заявили в феврале, что они не

14 Tridivesh Singh Maini, "Coronavirus and It's Impact on the Belt and Road," Modern Diplomacy, March 24, 2020, https://moderndiplomacy.eu/2020/03/24/coronavirusand-its-impact-on-the-belt-and-road.

15 Russel, "The Coronavirus Will Not Be Fatal for China's Belt."

16 Mordechai Chazizza, "The Impact of the Coronavirus Pandemic on China's Belt and Road Initiative in the Middle East," Middle East Institute, April 28, 2020, https://www.mei.edu/publications/impact-coronavirus-pandemic-chinas-belt-androad-initiative-middle-east.

17 "Deferral Sought on Signing Rail Contract," Bangkok Post, April 14, 2020, https://www.bangkokpost.com/business/1899110/deferral-sought-on-signing-railcontract.

18 National Bureau of Statistics of China, "Preliminary Accounting Results of GDP for the First Quarter of 2020," April 20, 2020, http://www.stats.gov.cn/english/PressRelease/ 202004/t20200420_1739811.html. 
смогут пережить еще один месяц изоляции, которая была отменена только в середине апреля. ${ }^{19}$

Немногие из тех компаний, которые пережили пандемию, вернулись к работе на полную мощность. Перезапуск цепочек поставок требует времени, а требования к инфекционному контролю снизили производительность и увеличили затраты. Отрасли промышленности, ориентированные на экспорт, также сталкиваются с проблемой низкого мирового спроса. Объем производства будет значительно ниже в течение 2020 и, возможно, 2021 года. Как следствие, безработица растет и вероятно достигнет уровня, невиданного долгое время. Официальное число безработных увеличилось на 3 миллиона в период с декабря 2019 года по март 2020 года до рекордных 5,9\%. Если бы около 50 миллионов рабочих-мигрантов, многие из которых не могут вернуться к своей работе в больших городах, были включены в статистику, количество людей, не имеющих работы, может легко увеличиться вдвое. ${ }^{20}$ Многие китайцы, потерявшие работу, будут изо всех сил пытаться выплатить долги. Таким образом, дефолт по ссуде также станет проблемой для компаний, которые уже сильно пострадали от последствий пандемии. Государственная банковская система Китая, вероятно, сможет абсорбировать большие суммы невыплаченных кредитов, хотя на самом деле никто не знает, насколько крепки государственные банки Китая, но кредитный кризис в стране ограничит возможность выдавать новые кредиты для дорогостоящих проектов ИМД. Это может поставить под сомнение проекты, которые все еще находятся на стадии планирования и, по крайней мере, приведет к пересмотру рентабельности. В прошлом китайские инвесторы очень быстро предоставляли ссуды даже для экономически неоднозначных проектов. Это, вероятно, изменится и более рискованные инвестиции могут быть отменены. Даже проекты ИМД в продвинутой стадии реализации могут столкнуться с проблемами, если рефинансирование старых кредитов станет более затруднительным.

Из-за исключительного экономического спада, отмеченного первым за десятилетия сокращением ВВП, руководство коммунистической партии находится под давлением, чтобы переориентировать внимание на внутренние инвестиции. Призывы к принятию большого пакета мер стимулирования становятся все громче, но партия все еще сопротивляется, потому что она уже ввела несколько программ расходов после глобального финансового кризиса 2007-2009 годов. Увеличение государственных расходов по-

19 Jiayan Feng, "More than 240,000 Chinese Companies Declare Bankruptcy in the First Two Months of 2020," SupChina, April 9, 2020, https://supchina.com/2020/04/09/ more-than-240000-chinese-companies-declare-bankruptcy-in-the-first-two-monthsof-2020.

20 Sun Yu and Christian Shepherd, "China Struggles with Sharp Rise in Unemployment," Financial Times, April 23, 2020, https://www.ft.com/content/5c172455-e967-45a584c8-47efc3788b08. 
могло стабилизировать замедляющийся рост ВВП в последние годы, но отдача от инвестиций сокращается по мере того, как Китай становится более развитым. Однако альтернативы государственным расходам как средству преодоления экономического шока, вызванного пандемией, нет и, хотя у Китая есть большие резервы, они уменьшились в последние годы отчасти из-за финансирования ИМД. Это означает, что Китай будет вынужден более осторожно расходовать средства и будет иметь меньше финансовых возможностей для иностранных инвестиций. Еще до пандемии в китайском Интернете увеличивалось количество постов, в которых ИМД называли «большой утечкой денег» (по-китайски: да са би), что вызывает удивление, поскольку цензоры изо всех сил пытаются подавить любую публичную критику политики правительства. ${ }^{21}$ Те же люди теперь требуют приоритезации внутренних расходов и отказа от ИМД, по крайней мере, на время.

\section{Перспективы для стран ИМД}

Ситуация на принимающей финансирование стороне инициативы «Один пояс, один путь» похожа или даже хуже. Страны-партнеры Китая озабочены борьбой с пандемией и ее экономическими последствиями. Многие страны Центральной Азии, Ближнего Востока и Африки недофинансируют системы общественного здравоохранения и особенно уязвимы. В настоящее время внимание будет уделяться спасению жизней и прекращению роста новых инфекций. Страны, столкнувшиеся с чрезвычайной ситуацией в области здравоохранения, вряд ли будут иметь возможность продвигать свои планы экономического развития.

В отличие от Китая, многие страны ИМД не смогут полностью запустить свою экономику в течение длительного времени. Когда они это сделают, потребуется экономическая помощь, чтобы поддержать их экономику. Для этой цели будет использована большая часть финансовых ресурсов, что ограничивает средства, которые могут быть инвестированы в проекты ИМД. Многие государственные деятели поймут, что они больше не могут позволить себе строительство новых автомагистралей, железных дорог, трубопроводов или портов. Те проекты, которые уже подвергались сомнению, станут еще более уязвимыми со стороны оппозиционных сил и местной общественности. Китайско-пакистанский экономический коридор со временем становится все более непопулярным среди пакистанцев, и правительство уже до пандемии изо всех сил пыталось защитить эту инициативу от критики. С 2017 года против китайского присутствия в Пакистане было направлено пять терактов. ${ }^{22}$ Кувейт также столкнулся с очень сильной политической критикой плюсов и минусов участия в программе «Один пояс,

21 "From the Party, with Love: China Releases a Movie Drama Featuring Its Belt-and-Road Project," The Economist, September 5, 2019, https://www.economist.com/china/ 2019/09/05/china-releases-a-movie-drama-featuring-its-belt-and-road-project.

22 Helen Blackwell, "Pakistan Refocuses on Counter-Terrorism to Protect China's Investments," International Institute for Strategic Studies (IISS), September 19, 2019, 
один путь». ${ }^{23}$ В Центральной Азии протесты против экономического влияния Китая и жалобы на их вмешательство во внутренние дела в 2019 году стали более громкими. ${ }^{24}$ Эти тенденции будут усиливаться, если недовольство Китаем как начальной точки вспышки заразы и его ролью в распространении вируса перевесит последствия китайской “дипломатии масок», которая включает предоставление медицинского оборудования и советников странам, пострадавшим от коронавируса. Страны, которые недовольны тем, как Китай справляется со вспышкой болезни, могут полностью пересмотреть свое более тесное сотрудничество с Китаем. Пандемия высветила негативные последствия участия в цепочке поставок, которая сильно ориентирована на Китай. Это может резко снизить энтузиазм по поводу участия в ИМД. Как видно из вышеизложенного, существует множество финансовых и политических причин, которые могут заставить страны отложить или даже отменить проекты ИМД.

Даже страны, которые хотят продолжать проекты ИМД в соответствии с планами, могут не иметь такой возможности. Целых 23 страны ИМД уже находились в долговом кризисе до пандемии, ${ }^{25}$ и стоимость борьбы с вирусом и спасения экономики еще больше увеличит риск невозврата кредитов. Некоторые из местных подрядчиков, участвующих в строительстве проектов ИМД, обанкротятся во время пандемии, что приведет к дальнейшим логистическим проблемам и задержкам. Задержки, связанные с прерыванием международных цепочек поставок и с проблемами национальной экономики, также сделают проекты ИМД более дорогими. Чтобы иметь возможность поддерживать ИМД, таким странам, как Камбоджа, Кыргызстан, ШриЛанка, Пакистан, Джибути или Черногория, потребуется списание долгов.

Однако вряд ли Китай будет массово списывать долги. Суммы настолько большие, что Китай не может себе позволить отказаться от выплат. Согласно анализу Кильского института мировой экономики, Китай одолжил развивающимся странам на 50 \% больше денег, чем он официально сообщил. Эти «скрытые долги» искажают международное наблюдение за практикой кредитования. Анализ показывает, что китайское правительство и государственные кредитные агентства предоставили займы на сумму 520 миллиардов долларов более чем 150 странам. Большая часть этих кредитов была

https://www.iiss.org/blogs/analysis/2019/09/sasia-pakistan-protects-chineseinvestments.

23 Sebastian Castelier, "Can Kuwait's Silk City Project Overcome Islamist Opposition in Parliament?," Al-Monitor, June 5, 2019, https://www.al-monitor.com/pulse/originals/ 2019/06/kuwait-silk-city-bump-unanticipated-obstacles.html.

24 Aruuke Uran Kyzy, "Why Is Anti-Chinese Sentiment on the Rise in Central Asia?," The Diplomat, October 8, 2019, https://thediplomat.com/2019/10/why-is-anti-chinesesentiment-on-the-rise-in-central-asia.

25 John Hurley, Scott Morris, and Gailyn Portelance, "Examining the Debt Implications of the Belt and Road Initiative from a Policy Perspective," Journal of Infrastructure, Policy and Development 3, no. 1 (2019): 139-175, https://doi.org/10.24294/jipd.v3i1.1123. 
выдана в последние годы на проекты, связанные с ИМД. В настоящее время на Китай приходится четверть общего объема банковских кредитов развивающимся странам, и он является крупнейшим официальным кредитором, превосходящим Всемирный банк или МВФ. ${ }^{26}$

Банк развития Китая и Экспортно-импортный банк Китая (EXIM) имеют достаточно ресурсов и политической поддержки для сохранения текущего уровня кредитования, но из-за коронавируса можно ожидать лавину просьб о пересмотре условий кредита. Китай пересмотрел условия большого количества кредитов, связанных с ИМД, хотя часто только в обмен на уступки со стороны стран-получателей, и похоже, что он хочет продолжить эту практику. ${ }^{27}$ В апреле 2020 года правительство Кыргызстана объявило, что ведет активные переговоры с правительством Китая и банком ЕXIM о реструктуризации долгов на 1,7 миллиарда долларов. ${ }^{28}$ Тем не менее, Китай может столкнуться с негативной реакцией внутри стран реципиентов из-за предложения более выгодных условий кредита, особенно если его нежелание списывать кредиты сохранится. Наиболее вероятный сценарий состоит в том, что периоды погашения будут увеличены, что не решит проблему долга, но, по крайней мере, позволит пока продолжить расширение ИМД. То, попадут ли страны, в конечном итоге, в дефолт по кредитам, зависит от доходов, которые они получат от завершенных проектов ИМД. История ранних проектов ИМД пока неоднозначна, что должно беспокоить не только партнеров ИМД, но и Пекин. Таким образом, пандемия коронавируса стала переломным моментом для ИМД.

\section{Дорога вперед}

Одной из причин, по которым Китай инициировал ИМД, было поддержание высоких темпов экономического роста внутри страны за счет увеличения своей доли в глобальных цепочках создания стоимости и расширения своих экспортных рынков. Теперь, когда коронавирус привел к падению ВВП (экономика Китая сократилась на 6,8 \% в первом квартале 2020 года), ИМД может стать еще более важной для экономической стратегии Пекина по поддержанию долгосрочного роста. Сейчас развивающийся мир нуждается в иностранных инвесторах и займах больше, чем когда-либо. А благодаря пандемии коронавируса будет еще меньше коммерческих, а также государственных инвесторов и кредиторов. Китай может оказаться единственной

26 Sebastian Horn, Carmen M. Reinhart, and Christoph Trebesch, "China's Overseas Lending," Working Paper 26050 (Cambridge, MA: National Bureau of Economic Research, 2019), https://doi.org/10.3386/w26050.

27 Agatha Kratz, Daniel H. Rosen, and Matthew Mingey, "Booster or Brake? COVID and the Belt and Road Initiative," Rhodium Group, April 15, 2020, https://rhg.com/ research/booster-or-brake-covid-and-the-belt-and-road-initiative.

28 Aida Dzhumashova, "Exim Bank of China to Reschedule Debt of Kyrgyzstan," 24.KG, April 29, 2020, https://24.kg/english/151447_Exim_Bank_of_China_to_reschedule_ debt_of_Kyrgyzstan_. 
страной, у которой все еще есть достаточно резервов для инвестиций в страны с формирующимся рынком и в развивающиеся страны. Это открывает возможности для установления новых отношений с ранее скептически настроенными режимами и может вынудить страны заключить сделки с Китаем просто потому, что в данный момент альтернативы нет. Пандемия также предлагает другие возможности для повышения позиций Китая в мире. Пекин изо всех сил пытается стать образцом для подражания в борьбе с COVID-19, чтобы повысить свой имидж и отвлечь внимание от собственных неудач на ранней стадии вспышки. Китай поспешил предложить медицинскую помощь в виде масок для лица, респираторов и бригад врачей. Эта «масочная дипломатия» уже принесла внешнеполитические выгоды. Когда в ЕС стало не хватать медицинских средств защиты и прекратился экспорт за пределы ЕС, страна-кандидат в ЕС Сербия заявила, что европейская солидарность мертва, и обратилась за помощью к Китаю. Этот инцидент может стать поворотным моментом для международной ориентации Сербии.

Кризис с коронавирусом также может придать новый импульс концепции "шелкового пути здоровья», которая в большинстве случаев игнорировалась несмотря на то, что она была частью ИМД с 2017 года. Китай имеет хороший послужной список в предоставлении финансирования для развития инфраструктуры здравоохранения в Азии и Африке. Более целенаправленная ориентация ИМД к здравоохранению могла бы помочь повысить признание на местном уровне глобальной экономической экспансии Китая на фоне растущей критики его «дипломатии долговых ловушек». Председатель КНР Си Цзиньпин уже начал чаще использовать термин «шелковый путь здоровья» в официальных беседах. Если Китай окажется крупным спонсором здравоохранения во время пандемии, страны, получающие помощь от Китая, будут иметь большее доверие и с большей вероятностью будут участвовать в сотрудничестве по программе ИМД. Однако пока рано говорить о том, сможет ли Китай извлечь выгоду из глобального кризиса в области здравоохранения. Многое будет зависеть от того, насколько хорошо он справляется с внутренними кризисами. Чем быстрее восстановится экономика Китая, тем раньше Пекин сможет перенаправить внимание и ресурсы на ИМД. Пандемия COVID-19, несомненно, станет препятствием для ИМД, но в следующие месяцы будет решено, будет ли это смертельным ударом или может ли она превратиться в долгосрочный стимул для ИМД в духе «то, что тебя не убивает, только делает тебя сильнее».

\section{Что это означает для стран ИМД?}

Учитывая столь неопределенный будущий результат, субъекты, принимающие политические решения в странах ИМД, сталкиваются с трудным решением: продолжать ли ИМД и надеяться на быстрое восстановление мировой экономики или отказаться от проектов ИМД, чтобы минимизировать потери. Пандемия COVID-19 глубоко изменила расчеты рентабельности 
стран, участвующих в ИМД. Проекты, добавленная стоимость которых была неопределенной до пандемии, вероятно больше не стоят дальнейшего риска. Однако некоторые страны уже настолько много инвестировали в ИМД и так сильно задолжали Китаю, что больше не могут выйти из нее. Другие страны могут продолжать рассматривать ИМД как единственный шанс для экономического развития. Эти страны могут только попытаться как можно лучше смягчить негативные последствия пандемии, что нелегко сделать, поскольку большинство срывов произошло на китайской стороне соглашения. Попытка повысить устойчивость проектов за счет многосторонности ИМД может быть целесообразной мерой. Китай уже начал быть более открытым для проектов с участием многих заинтересованных сторон, поскольку ИМД становится все более дорогим. Учитывая негативную реакцию, вызванную пандемией, увеличились шансы убедить Китай отказаться от части своего контроля над ИМД. Разрешение многосторонним институтам и иностранным банкам финансировать проекты ИМД не только снизит зависимость от Китая и диверсифицирует риски, но также повысит прозрачность и, возможно, даже окажет положительное влияние на эффективность и устойчивость. Пересмотр существующих займов может дать дополнительную передышку и, хотя маловероятно, что Китай пойдет на существенные финансовые уступки, он дает возможность пересмотреть условия использования внутренних источников финансирования и привлечь местные компании, тем самым увеличивая положительное экономическое влияние в странах ИМД. Шансы договориться с Китаем о более выгодных условиях сотрудничества никогда не были лучше, потому что ИМД стал слишком важным с точки зрения внешней политики и слишком большим с экономической точки зрения, чтобы он потерпел неудачу.

\section{Отказ от ответственности}

Выраженные здесь взгляды являются исключительно взглядами автора и не отражают точку зрения Консорциума оборонных академий и институтов изучения безопасности ПрМ, участвующих организаций или редакторов Консорциума.

Издание Connections: The Quarterly Journal, том 19, 2020 осуществляется при поддержке правительства Соединенных Штатов.

\section{6 авторе}

Франк Моуриц - научный сотрудник Центра им. Маршалла и Университета Бундесвера в Мюнхене. Он является докторантом Кельнского университета и имеет степень магистра международной политики и исследований по Восточной Азии Университета Уорик со специализацией по международной политической экономии Азиатско-Тихоокеанского региона. Его исследования сосредоточены на геоэкономике, международной экономической взаимозависимости и безопасности в Восточной Азии. 